\title{
Opposite effects of cyclooxygenase-1 and -2 activity on the pressor response to angiotensin II
}

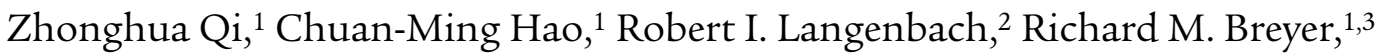 \\ Reyadh Redha, ${ }^{1}$ Jason D. Morrow, ${ }^{1,3}$ and Matthew D. Breyer ${ }^{1,4,5}$
}

${ }^{1}$ Division of Nephrology, Department of Medicine, Vanderbilt University School of Medicine, Nashville, Tennessee, USA
${ }^{2}$ Laboratory of Experimental Carcinogenesis and Mutagenesis, National Institute of Environmental Health Sciences,
Research Triangle Park, North Carolina, USA
${ }^{3}$ Department of Pharmacology, Vanderbilt University School of Medicine, Nashville, Tennessee, USA
${ }^{4}$ Department of Molecular Physiology and Biophysics, Vanderbilt University School of Medicine, Nashville, Tennessee, USA
${ }^{5}$ Veterans Administration Medical Center, Nashville, Tennessee, USA

Therapeutic use of cyclooxygenase-inhibiting (COX-inhibiting) nonsteroidal antiinflammatory drugs (NSAIDs) is often complicated by renal side effects including hypertension and edema. The present studies were undertaken to elucidate the roles of COX1 and COX2 in regulating blood pressure and renal function. COX2 inhibitors or gene knockout dramatically augment the pressor effect of angiotensin II (Ang II). Unexpectedly, after a brief increase, the pressor effect of Ang II was abolished by COX1 deficiency (either inhibitor or knockout). Ang II infusion also reduced medullary blood flow in COX2-deficient but not in control or COX1-deficient animals, suggesting synthesis of COX2-dependent vasodilators in the renal medulla. Consistent with this, Ang II failed to stimulate renal medullary prostaglandin $\mathrm{E}_{2}$ and prostaglandin $\mathrm{I}_{2}$ production in COX2deficient animals. Ang II infusion normally promotes natriuresis and diuresis, but COX2 deficiency blocked this effect. Thus, COX1 and COX2 exert opposite effects on systemic blood pressure and renal function. COX2 inhibitors reduce renal medullary blood flow, decrease urine flow, and enhance the pressor effect of Ang II. In contrast, the pressor effect of Ang II is blunted by COX1 inhibition. These results suggest that, rather than having similar cardiovascular effects, the activities of COX1 and COX2 are functionally antagonistic.

J. Clin. Invest. 110:61-69 (2002). doi:10.1172/JCI200214752.

\section{Introduction}

Nonsteroidal antiinflammatory drugs (NSAIDs) and cyclooxygenase-2-selective selective inhibitors (COXIBs) are widely prescribed for the treatment of arthritis pain and fever (1). Their long-term use is limited by the development of hypertension, edema, and congestive heart failure in a significant proportion of patients (2-4). NSAIDs block the activity of both cyclooxygenase (COX) isozymes, COX1 and COX2, which mediate the enzymatic conversion of arachidonate to prostaglandin $\mathrm{H}_{2}\left(\mathrm{PGH}_{2}\right)$ and other prostaglandin metabolites (5-7). It is well established that the afore-

Received for publication November 30, 2001, and accepted in revised form May 14, 2002.

Address correspondence to: Matthew D. Breyer,

F-427 ACRE Building, Veterans Administration Medical Center,

Nashville, Tennessee 37212, USA.

Phone: (615) 327-4751 ext. 5492; Fax: (615) 343-7156;

E-mail: Matthew.Breyer@mcmail.vanderbilt.edu.

Conflict of interest: No conflict of interest has been declared.

Nonstandard abbreviations used: nonsteroidal

antiinflammatory drugs (NSAIDs); cyclooxygenase 1 (COX1); cyclooxygenase 2 (COX2); cyclooxygenase-2-selective selective inhibitors (COXIBs); prostaglandin $\mathrm{H}_{2}\left(\mathrm{PGH}_{2}\right)$;

thromboxane $\mathrm{A}_{2}\left(\mathrm{TxA}_{2}\right)$; mean arterial pressure (MAP); medullary blood flow (MBF); cortical blood flow (CBF); angiotensin converting enzyme (ACE). mentioned deleterious cardiovascular profile of NSAIDs can be accounted for by inhibition of COXdependent prostaglandin synthesis (8-10).

Following the COX-mediated synthesis of $\mathrm{PGH}_{2}$ from arachidonate, $\mathrm{PGH}_{2}$ is metabolized to one of at least five bioactive prostaglandins, including $\mathrm{PGE}_{2}$, $\mathrm{PGI}_{2}, \mathrm{PGF}_{2 \alpha}, \mathrm{PGD}_{2}$, or thromboxane $\mathrm{A}_{2}\left(\mathrm{TxA}_{2}\right)(5,11$, 12). These prostanoids have pleiotropic cardiovascular effects altering platelet function (13-15) and renal function (2), and acting either as vasodilators or vasoconstrictors (16-19). Whereas $\mathrm{PGI}_{2}$ is a vasodilator $(18$, 20), $\mathrm{TxA}_{2}$ is a vasoconstrictor $(8,21)$, while $\mathrm{PGE}_{2}$, which may interact with four distinct receptors, can act either as a vasodilator or a vasoconstrictor depending on the accessibility of the specific receptors (16, 22). Although COX1 and COX2 exhibit similar biochemical activity in converting arachidonate to $\mathrm{PGH}_{2}$ in vitro $(13,23)$, the ultimate prostanoids they produce in vivo may be different $(15,24)$ due to differential regulation of $\operatorname{COX} 1$ and $\operatorname{COX} 2(6,7,25,26)$, tissue distribution $(2,25,26)$, and availability of the downstream prostanoid synthases $(24,27,28)$. Given the potential heterogeneity in the spectrum of prostanoids synthesized by a given cell, and the available downstream receptors, the net effect of COX inhibition on the cardiovascular system may be quite unpredictable. 
Renal medullary prostaglandins have been established as being critically involved in mitigating hypertension, helping to maintain medullary blood flow $(\mathrm{MBF})$, and promoting urinary salt excretion (29-31). Both COX1 and COX2 are abundantly expressed in the renal medulla; however, the relative contributions of COX1 and COX2 to synthesis of the prostaglandins, which help maintain renal $\mathrm{MBF}$, tubular transport rates, and urine formation, remain uncertain. Interestingly, the COX1 and COX2 isoforms are differentially localized in the renal medulla, as demonstrated in rats, rabbits, and humans, with COX1 expressed primarily in collecting duct and COX2 predominantly in interstitial cells $(25,26,32)$. The purpose of the present studies was to determine the contribution of COX1 and COX2 activity to urine formation, $\mathrm{MBF}$, and regulation of systemic blood pressure.

\section{Methods}

Materials. The COX1-selective inhibitor SC58560 and the COX2-selective inhibitor SC58236 were generously provided by Peter C. Isakson and Karen Seibert (Pharmacia, St. Louis, Missouri, USA). Stock solutions of COX1 and COX2 inhibitors were made by dissolving them into a solution of $95 \%$ polyethylene glycol 200 and 5\% Tween-20. For chronic feeding, the COX2 inhibitor ( $3 \mathrm{mg} / \mathrm{ml}$ stock solution) or COX1 inhibitor (15 $\mathrm{mg} / \mathrm{ml}$ in stock solution) was diluted 1:500 in tap water and given ad libitum in the drinking water as previously described (33). For the acute-infusion studies, COX1 or COX2 inhibitors $(20 \mathrm{mg} / \mathrm{ml}$ stock solution) were diluted with $0.9 \%$ sodium chloride containing $1 \%$ BSA. Ang II was purchased from Sigma-Aldrich (St. Louis, Missouri, USA). The COX1 polyclonal antibody was from Santa Cruz Biotechnology Inc. (Santa Cruz, California, USA; catalog no. SC1752). The COX2 polyclonal antibody was purchased from Cayman Chemical Co. (Ann Arbor, Michigan, USA; catalog no. 160106). C57BL/6J female mice were obtained from The Jackson Laboratory (Bar Harbor, Maine, USA). The wild-type and homozygous null mice used in the present study originated from the heterozygous COX1 or COX2 agouti mice (50\% $1290 \mathrm{Ola} / 50 \%$ C57BL/6) initially produced $(34,35)$. Both genotypes had been individually maintained using a heterozygous by heterozygous cross breeding strategy for more than 20 generations (Figure 1).

Surgical preparation. Experiments were conducted using female C57BL/6J mice, or female COX1- and COX2-deficient mice. Mice were anesthetized with ketamine plus inactin as described previously (10). After tracheostomy, a PE10 cannula was placed in the left carotid artery for monitoring mean arterial pressure (MAP). Another PE10 catheter was inserted into the jugular vein for intravenous infusion. A PE50 catheter was inserted into the bladder for collection of urine. The left kidney was exposed by midline laparotomy. A laser-Doppler flowmeter (model BLF 21D; Transonic Systems Inc., Ithaca, New York, USA) equipped with two flow probes was used to measure renal cortical blood flow $(\mathrm{CBF})$ and $\mathrm{MBF}$. One flow probe (type $\mathrm{N}$ probe with a 3-mm diameter) was placed on the surface of the kidney to measure $\mathrm{CBF}$. MBF was measured by a monofilament fiberoptic flow probe (diameter $0.5 \mathrm{~mm}$ ) implanted into the renal medulla. The location of the implanted fiber probe was confirmed at the end of each experiment by dissecting the kidney and examining the region surrounding the fiber tip. Data from incorrectly positioned fibers were discarded. After surgery, mice received continuous infusion of $0.9 \%$ sodium chloride containing $1 \% \mathrm{BSA}$ at a rate of $0.5 \mathrm{ml} / \mathrm{h}$ and allowed to equilibrate for about 120 minutes. MAP was analyzed using a Blood Pressure Analyzer (BPA model 300; Micro-Med Inc., Louisville, Kentucky, USA). Using this approach we determined that blood pressure, $\mathrm{CBF}$, and $\mathrm{MBF}$ remained stable during the period from 120 to 200 minutes after surgery in control (vehicle-treated) animals.

Protocol 1: chronic pretreatment with COX1 or COX2 inbibitors, or using COX1- or COX2-deficient mice. C57BL/6J female mice were randomly assigned to three groups, and the COX1 inhibitor, COX2 inhibitor, or vehicle was orally administered for 7 days. Normal diet was accessed freely. After surgery and equilibration, baseline measurements were determined for 20 minutes. The mice were then intravenously infused with Ang II at a rate of $150 \mathrm{pmol} / \mathrm{kg} / \mathrm{min}$, in $0.5 \mathrm{ml} / \mathrm{h}$ for $30 \mathrm{~min}$ utes. In the third period, the effect of combined infusion of Ang II (150 pmol $/ \mathrm{kg} / \mathrm{min})$ and COX2 inhibitor $(33.3 \mu \mathrm{g} / \mathrm{kg} / \mathrm{min}$ intravenously) was determined. MAP, $\mathrm{CBF}$, and $\mathrm{MBF}$ were continuously recorded and urine samples were collected during each period. Studies in

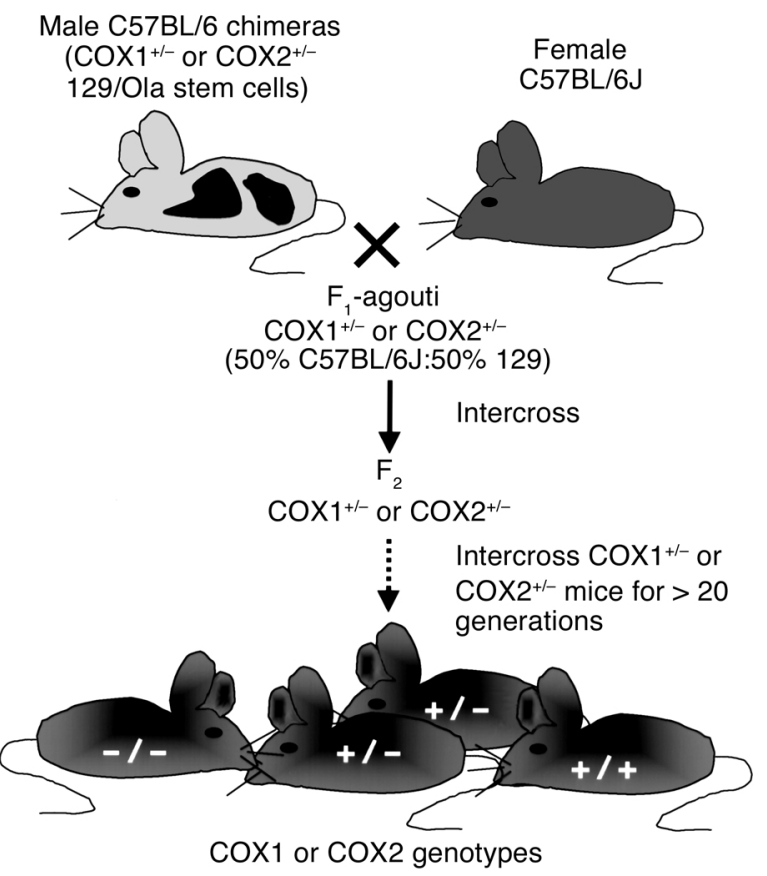

Figure 1

Breeding scheme for COX1 and COX2 knockout and wild-type mice used in these studies (see Methods for details). 
COX1- and COX2-deficient mice and their wild-type littermates were conducted similarly, except for omitting pretreatment with COX inhibitors.

Protocol 2: effects of acute infusion of selective COX inbibitors. After the initial equilibration period and base-line data collection, mice were administered a continuous infusion of the COX 1 or COX 2 inhibitor at $33.3 \mu \mathrm{g} / \mathrm{kg} / \mathrm{min}$ over 30 minutes. MAP, CBF, and MBF were recorded continuously, and urine samples were collected.

Immunohistochemistry. Mouse tissue was fixed with glutaraldehyde-periodate acid saline as described previously (26). The kidney was then dehydrated with a graded series of ethanol and embedded in paraffin. Sections were cut at $4 \mu \mathrm{m}$ thickness, and immunostained with anti-murine COX1 (1:200 dilution) or COX2 antibody (1:500 dilution). Vectastain ABC-Elite (Vector Laboratories Inc., Burlingame, California, USA) was used to localize the primary antibodies.

Determination of renal medullary prostanoid levels. Following acute physiologic studies, mouse kidneys were removed and dissected into cortex and medulla and snap-frozen in liquid nitrogen. Prostanoid levels (including $\mathrm{PGE}_{2}$, 6-keto-PGF1 $\alpha$, PGF2 $\alpha$, and $\mathrm{TxB}_{2}$ ) were quantified by gas chromatographic/negative ion chemical ionization mass spectrometric assays as described previously (36).

Measurement of gastric mucosal $P G E_{2}$ level and urinary sodium. Gastric mucosal $\mathrm{PGE}_{2}$ synthesis was determined as a measure of endogenous COX1 activity (37). Mucosal linings of stomachs from control and experimental animals were harvested and homogenized in 0.1 sodium phosphate buffer containing $15 \%$ methanol. Samples were centrifuged at $12,000 \mathrm{~g}$ at $4^{\circ} \mathrm{C}$. Supernatants were passed through a C-18 column (Waters Corp., Milford, Massachusetts, USA). PGE $_{2}$ was eluted in $1 \mathrm{ml}$ of ethylacetate and determined by enzyme immunosorbent assay ( $\mathrm{PGE}_{2}$ enzyme immunoassay kit; Oxford Biomedical Research Inc., Oxford, Michigan, USA).

Measurement of urinary electrolytes. Urinary sodium concentration was measured using an automatic flame

\section{Figure 2}

Distinct effects of COX1 and COX2 on systemic arterial pressure. (a) The change in MAP ( $\triangle M A P)$ following infusion of Ang II at $150 \mathrm{pmol} / \mathrm{kg} / \mathrm{min}$ (between 10 and 40 minutes) and the addition of a COX2 inhibitor, SC58236 (between 40 and 70 minutes) in vehicle-treated mice (circles, $n=5$ ); mice pretreated with SC58560, a COX1 inhibitor (triangles, $n=8$ ); and mice pretreated with SC58236, the COX2 inhibitor (squares, $n=8$ ). Ang II elevated MAP in vehicle-pretreated mice; the elevation was further increased upon addition of the COX2 inhibitor. Ang II increased significantly more in mice orally pretreated with the COX2 inhibitor, and significantly less in mice pretreated with the COX1 inhibitor $\left({ }^{\#} P<0.05\right.$ vs. control). (b) Ang II induced a higher increase of MAP in COX2 knockout mice (open squares, $n=6$ ) than in wild-type controls (filled squares, $n=5$; ${ }^{\#}<<0.05$ ). Additional COX2 inhibitor infusion further elevated MAP only in wild-type mice. (c) The pressor effect of Ang II was attenuated in COX1 knockout mice (open triangles, $n=6$ ) versus wild-type controls (filled triangles, $n=5 ;{ }^{*} P<0.05$ ). MAP was further elevated by acute infusion of the COX2 inhibitor in both COX1 knockout and wildtype mice. ${ }^{*} P<0.05$ vs. MAP at 40 minutes. photometer (model IL943; Instrumentation Laboratory Inc., Lexington, Massachusetts, USA).

Statistical analysis. All data are presented as mean \pm SE. A paired $t$ test was used to analyze changes of renal hemodynamics and systemic blood pressure within the same group. ANOVA and Bonferroni $t$ test was used for analysis of difference between groups. Statistical significance was identified at $P<0.05$.

\section{Results}

Opposing effects of COX 1 and COX 2 on blood pressure. The contribution of COX1 and COX2 to the maintenance of blood pressure was examined in anesthetized mice. Baseline MAP was similar in control mice $(98.4 \pm 3.6 \mathrm{mmHg}$, $n=9)$, $\mathrm{COX}^{-/-}$mice $(87.5 \pm 3.8 \mathrm{mmHg}, n=18)$, COX2 ${ }^{-/-}$ mice $(92.8 \pm 5 \mathrm{mmHg}, n=12)$, mice pretreated with the COX1 inhibitor $(98.6 \pm 2.1 \mathrm{mmHg}, n=15)$, and COX2 inhibitor-treated mice $(96.3 \pm 2.5 \mathrm{mmHg}, n=18)$. In contrast, following intravenous infusion of Ang II (150 $\mathrm{pmol} / \mathrm{kg} / \mathrm{min})$, MAP increased by $16.5 \pm 1.9 \mathrm{mmHg}$ at
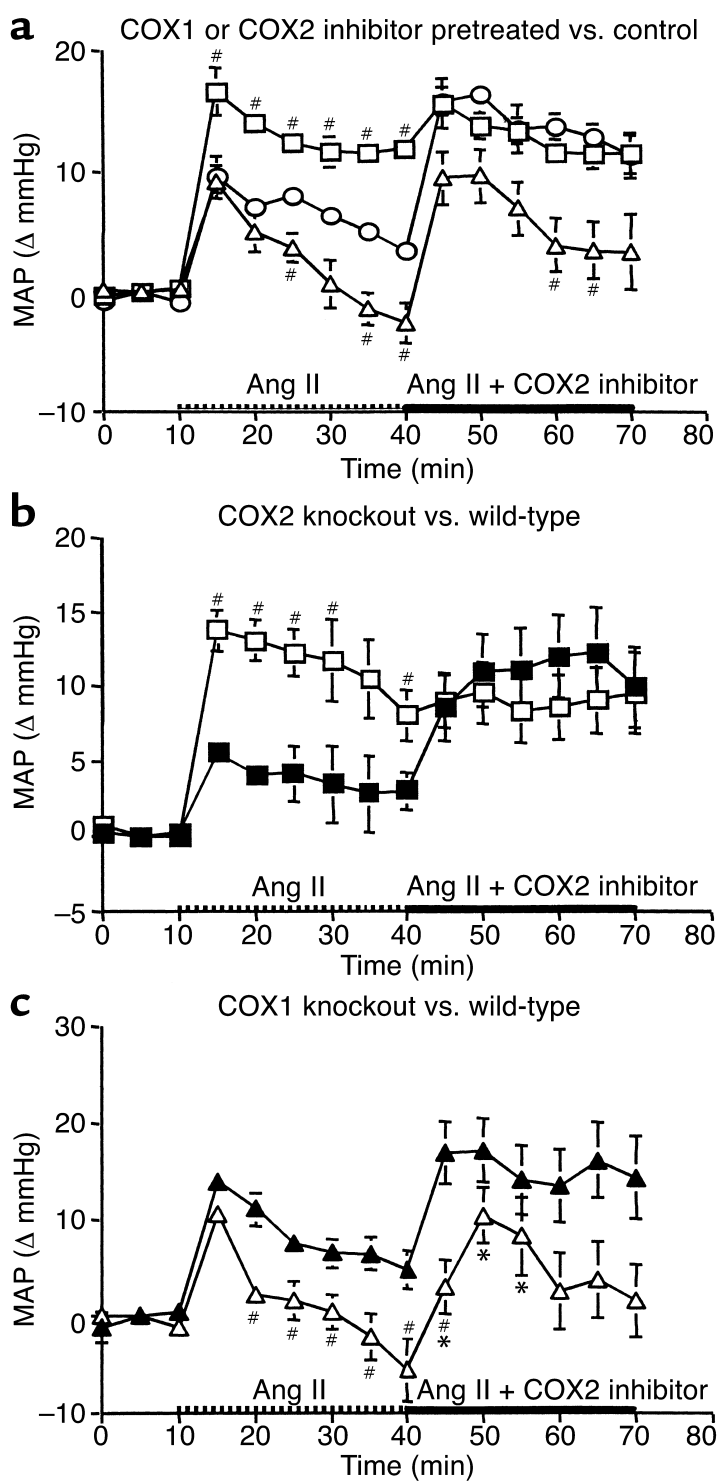

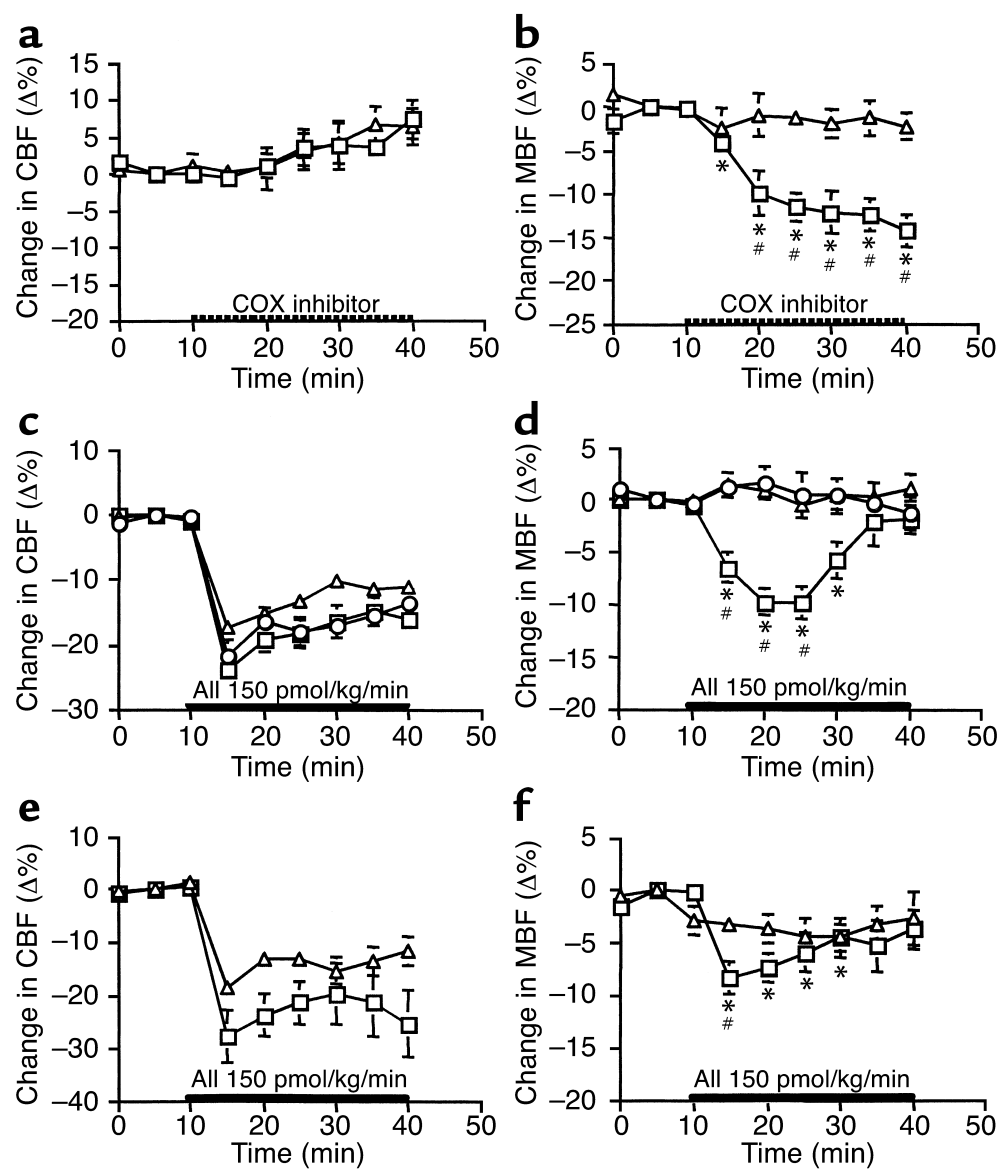

\section{Figure 3}

Effects of selective COX1 versus COX2 inhibition on cortical and medullary blood flow. (a and $\mathbf{b}$ ) The effect of acute infusion of the COX1 inhibitor (triangles, $n=5$ ) or COX2 inhibitor (squares, $n=4$ ) on $\mathrm{CBF}$ and MBF in normal mice. ${ }^{*} P<0.05$ vs. base-line MBF at 10 minutes; ${ }^{\#} P<0.05$ vs. MBF in the COX 1 inhibitor-infused mice. (c and $\mathbf{d}$ ) The effect of continuous Ang II infusion on $\mathrm{CBF}$ and $\mathrm{MBF}$ in mice pretreated with the COX2 inhibitor (squares, $n=7$ ), COX1 inhibitor (triangles, $n=8$ ), or vehicle (control group, circles, $n=5$ ). ${ }^{*} P<0.05$ vs. base-line MAP at 10 minutes; ${ }^{\#} P<0.05$ vs. control or COX1 inhibitor-treated mice. (e and $\mathbf{f}$ ) The effects of Ang II infusion on CBF and MBF in COX2 knockout (squares, $n=6$ ) and COX1 knockout mice (triangles, $n=6) .{ }^{*} P<0.05$ vs. base-line MAP at 10 minutes; ${ }^{\#} P<0.05$ vs. COX1 knockout mice.

knockout mice as compared with their respective controls (Figure 2, b and c). Subsequent intravenous administration of the COX2 inhibitor did not affect MAP in COX2 knockout mice; however, it significantly increased the Ang II pressor response in COX1 knockout mice, COX1 inhibitor-pretreated mice, and controls supporting the presence of dilator prostanoids in these three groups.

Distinct effects of COX1 and COX2 inbibition on renal cortical and medullary blood flow. MBF is a critical determinant of urinary salt excretion and systemic blood

5 minutes in mice pretreated with the COX 2 inhibitor (Figure 2a), or nearly twice as much as in control mice $(\Delta+9.6 \pm 1.4 \mathrm{mmHg})$. In control mice, this initial pressor effect was followed, over 30 minutes, by a gradual decline in MAP to only $3.3 \pm 0.4 \mathrm{mmHg}$ above base-line $(P<0.01$ vs. base-line). The sustained pressor effect of Ang II was approximately four times greater in mice pretreated with the COX2 inhibitor $(\Delta+11.7 \pm 0.8 \mathrm{mmHg}$ at 30 minutes) than in controls $(P<0.05)$. This suggests that COX2 activity normally generates a vasodepressor that moderates the pressor effect of Ang II.

Unexpectedly, the pressor effect of Ang II was markedly attenuated in mice pretreated orally with the COX1 inhibitor. Although the initial pressor effect at 5 minutes was no different from control $(\Delta+9.1 \pm 1.3$ $\mathrm{mmHg}$ above base-line), MAP rapidly fell below baseline levels within 30 minutes, so that at 30 minutes, MAP was significantly lower than in vehicle-treated controls $(\triangle \mathrm{MAP}=-2.7 \pm 1.7 \mathrm{mmHg}$ vs. $+3.3 \pm 0.4$ $\mathrm{mmHg} ; P<0.05)$. Similar divergent effects of Ang II on blood pressure were observed in COX1 and COX2

\section{Figure 4}

Distribution of COX1 and COX2 in mouse kidney. COX1 immunoreactivity in mouse outer medulla and papilla ( $\mathbf{a}$ and $\mathbf{b}$ ). COX2 immunoreactivity in cortex and medulla, respectively (c and $\mathbf{d}$ ). Arrows indicate a vascular bundle in $\mathbf{a}$ and an intermediate-size arteriole in $\mathbf{c}$. pressure. Because NSAIDs have previously been shown to reduce MBF (29), we examined the effect of isozyme-selective inhibitors in regulating renal CBF and MBF (Figure 3, a and b). Base-line MBF was determined in anesthetized mice. Subsequent infusion of a COX1-selective inhibitor did not affect CBF, MBF, or MAP (MAP data not shown). In contrast, infusion of a COX2 inhibitor significantly reduced $\operatorname{MBF}(-9.72 \pm 1.49 \%, n=7 ; P<0.001)$ (Figure 3b) without altering either CBF or MAP.
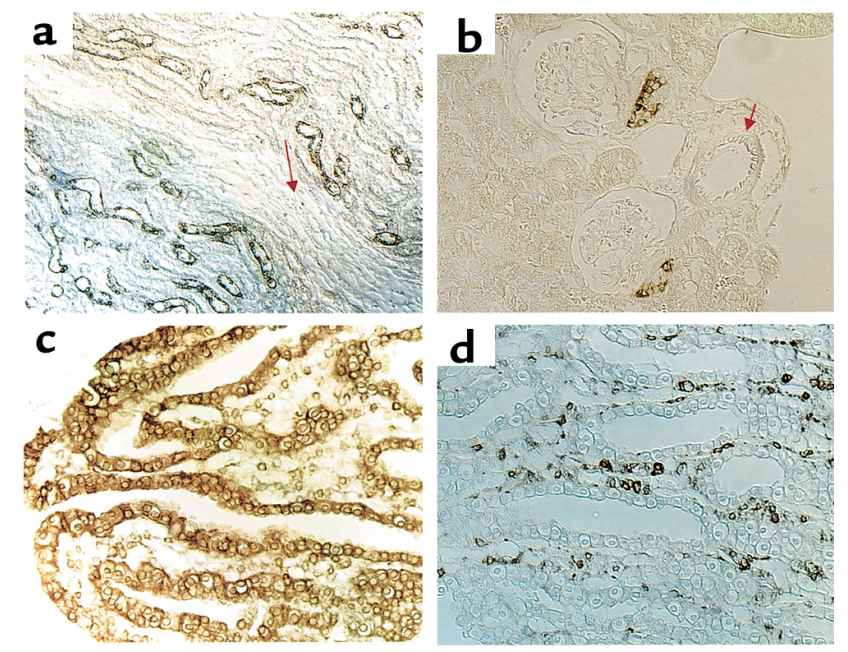


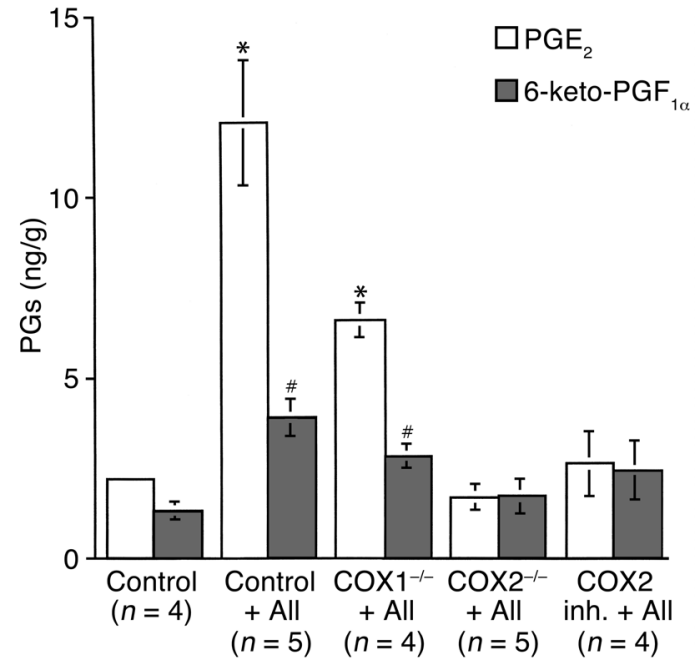

Figure 5

Effect of Ang II infusion and COX1 and COX2 deficiency on renal medullary $\mathrm{PGE}_{2}$ and $\mathrm{PGI}_{2}$ synthesis. Prostanoids were measured by gas chromatography/mass spectrscopy in snap-frozen papillae dissected from mice pretreated with the COX2 inhibitor (COX2 inh.), vehicle-treated mice, or COX knockout mice with or without acute infusion of Ang II for 30 minutes. ${ }^{*} P<0.01$ and ${ }^{\#} P<0.05$ vs. control.

Increased MBF is an important adaptation to hypertension, contributing to the so-called pressure natriuresis $(29,31)$. Together with its effects on MAP (described above), the effects of Ang II infusion on MBF were determined in the presence or absence of COX inhibitors. In control mice, Ang II (150 pmol $/ \mathrm{kg} / \mathrm{min}$ intravenously) had no effect on MBF (Figure 3d) but dramatically reduced CBF (Figure 3c). Pretreatment with a COX1 inhibitor did not modify the effect of Ang II on either $\mathrm{CBF}$ or MBF. In contrast, Ang II significantly reduced $\mathrm{MBF}$ in mice pretreated with a COX2 inhibitor (Figure $3 \mathrm{~d})$. Ang II infusion also reduced MBF in COX2 knockout mice, but not in COX1 knockout mice (Figure 3f). The effects of Ang II on CBF were not different in control versus inhibitor-treated mice, or in COX1 knockout versus COX2 knockout mice (Figure 3 ).
Differential distribution of COX1 and COX2. Because prostanoids generally act in an autocrine or paracrine fashion, we further investigated the basis for the different effects of COX1 and COX2 inhibitors on MBF by mapping the distribution of COX isozymes in mouse renal medulla (Figure 4). As reported for other species $(25,26,38)$, COX2 immunoreactivity predominated in renal medullary interstitial cells (Figure 4d), while COX1 expression predominated in collecting ducts (Figure 4b). Neither COX1 nor COX2 immunoreactivity was detected in outer medullary vascular bundles (Figure 4a). Similarly, COX2 was not detected in small arterioles in cortical vasculature, despite its detection, as expected, in the macula densa (Figure 4c).

Differential renal medullary prostaglandin production by COX1 and COX2. To further examine the mechanism underlying the distinct effects of COX1 versus COX2 inhibition on renal MBF, we determined the profile of prostaglandin synthesis in renal medulla harvested from control mice and mice pretreated with selective COX1 and COX2 inhibitors, as well as $\mathrm{COX}^{-/-}$and $\mathrm{COX}^{-/-}$mice, following Ang II infusion. Ang II infusion increased $\mathrm{PGE}_{2}$ synthesis 5.7 -fold $(P<0.01)$ and synthesis of the prostacyclin metabolite 6-keto-PGF1 $\alpha 2.7$-fold $(P<0.01)$ (Figure 5). In contrast, Ang II infusion did not alter tissue $\mathrm{TxB}_{2}, \mathrm{PGF} 2 \alpha$, or $\mathrm{PGD}_{2}$ (data not shown).

COX2 inhibition or gene disruption completely blocked the Ang II-induced increase in renal medullary $\mathrm{PGE}_{2}$ and 6-keto-PGF1 $\alpha$. In contrast, COX1 gene disruption did not prevent Ang II-stimulated renal medullary $\mathrm{PGE}_{2}$ and 6 -keto-PGF1 $\alpha$ production. These data show that Ang II stimulates the production of renal medullary $\mathrm{PGE}_{2}$ and $\mathrm{PGI}_{2}$ production through a COX2-dependent mechanism.

Distinct effects of COX1 and COX2 on urine volume and sodium excretion. Increased urine sodium and water excretion constitute a critical renal adaptation to hypertension, which normally corrects blood pressure $(29,39)$. The role of COX1 and COX2 activity in modulating renal water and electrolyte excretion was examined in anesthetized mice. Acute intravenous infusion of the
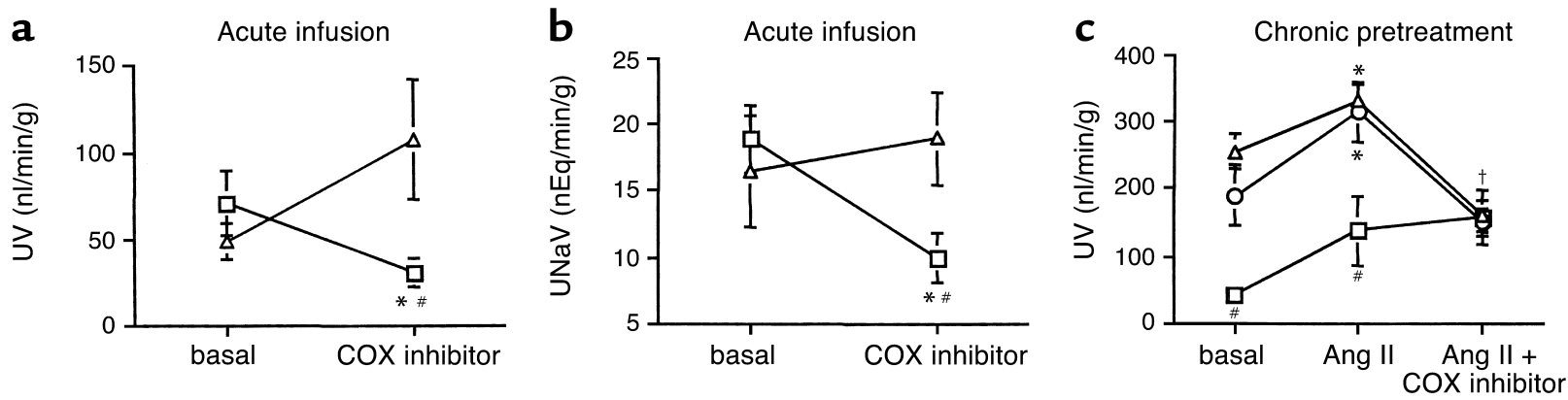

\section{Figure 6}

(a and b) Effect of isozyme-selective COX inhibition on urinary volume (UV) (a) and sodium excretion (UNaV) (b). Urinary volume and sodium excretion were significantly reduced in mice receiving acute infusion of the COX2 inhibitor SC58236 (squares, $n=7$ ) over 30 minutes, but not the COX1 inhibitor SC58560 (triangles, $n=5$ ). ${ }^{*} P<0.05$ vs. base-line; ${ }^{\#} P<0.05$ vs. the COX 1 inhibitor. (c) The change in UV following acute Ang II infusion and sequential addition of Ang II plus a COX2 inhibitor in mice orally pretreated with the COX1 inhibitor (triangles, $n=12$ ), COX2 inhibitor (squares, $n=8$ ), and vehicle-treated controls (circles, $n=6$ ). ${ }^{*} P<0.05$ vs. base-line; ${ }^{\#} P<0.05$ vs. control or COX1 inhibitor-pretreated mice; $\uparrow P<0.05$ in controls and mice pretreated with COX1 inhibitor vs. UV stimulated by Ang II only. 


\section{Table 1}

Basal urine volume and basal urinary sodium excretion in mice pretreated 7 days with COX1 inhibitor, COX2 inhibitor, or vehicle, as well as in COX1- and COX2-deficient mice

\begin{tabular}{|c|c|c|}
\hline & $\begin{array}{c}\text { UV } \\
(\mathrm{nl} / \mathrm{min} / \mathrm{g} \text { bw) }\end{array}$ & $\begin{array}{c}\mathrm{UNaV} \\
(\mathrm{nEq} / \mathrm{min} / \mathrm{g} \mathrm{bw})\end{array}$ \\
\hline Control $(n=6)$ & $189.83 \pm 45.72$ & $29.24 \pm 15.98$ \\
\hline COX1 inhibitor $(n=12)$ & $254.79 \pm 86.91$ & $40.37 \pm 15.95$ \\
\hline COX2 inhibitor $(n=8)$ & $43.24 \pm 23.74^{\mathrm{A}, \mathrm{B}}$ & $0.47 \pm 7.39^{B}$ \\
\hline $\operatorname{Cox}^{1 /-}(n=10)$ & $129.74 \pm 31.97$ & $22.98 \pm 13.65$ \\
\hline $\mathrm{COX}^{-/-}(n=8)$ & $49.61 \pm 6.37 c$ & $11.56 \pm 6.30^{C}$ \\
\hline
\end{tabular}

$\mathrm{UV}$, urinary volume; $\mathrm{UNaV}$, sodium excretion. ANOVA analysis: ${ }^{A} P<0.05$ vs. control; ${ }^{B} P<0.05$ vs. COX1 inhibitor. $t$ test analysis: ${ }^{C} P<0.05$ vs. $C O X 1^{-1-}$. bw, body weight.

COX1 inhibitor in control mice did not significantly change either urine volume or urinary sodium excretion (Figure 6, a and b). In contrast, both urine volume and sodium were significantly reduced $(P<0.05)$ following infusion of the COX2 inhibitor (Figure 6, a and b). These effects appear to be sustained, since mice chronically pretreated with the oral COX2 inhibitor exhibited reduced base-line urinary sodium excretion as compared with control or COX1 inhibitor-pretreated mice (Table 1). Similarly, basal urine volume and sodium excretion were significantly reduced in COX2 knockout mice versus COX1 knockout mice (Table 1).

Pretreatment with the COX2 inhibitor also significantly blunted the natriuresis and diuresis following Ang II infusion (150 pmol/ $\mathrm{kg} / \mathrm{min}$ ) (Figure 6c), as compared with the COX1 inhibitor or vehicle treatment. This occurred despite the fact that MAP was higher in Ang II-infused, COX2-inhibited mice than in the other groups (Figure 2a). Finally, infusion of the COX2 inhibitor in COX1-deficient or control mice acutely reduced urine volume and sodium excretion but had no additional effect on mice orally pretreated with the COX2 inhibitor.

Biological activity of the COX1 inbibitor. Since the COX1 inhibitor did not significantly alter renal blood flow or renal medullary prostaglandin production, we wished to confirm the in vivo activity of this compound. The capacity of SC58560 to inhibit gastric mucosal PGE 2 synthesis was determined in microsomes harvested from the same mice in which renal blood flow was measured (Figure 7). COX1 knockout mice exhibit a markedly reduced gastric mucosal $\mathrm{PGE}_{2}$ production as compared with controls, and this effect was reproduced by either chronic oral pretreatment (7 days) or acute intravenous infusion of the COX1 inhibitor (SC58560). In contrast, neither oral pretreatment nor acute intravenous infusion of the COX2 inhibitor (SC58236) reduced gastric mucosal $\mathrm{PGE}_{2}$ production, confirming the selectivity of the COX2 inhibitor used.

\section{Discussion}

The present studies were designed to elucidate the respective contribution of COX 1 and $\operatorname{COX} 2$ to the maintenance of systemic blood pressure and renal hemodynamics. These results define distinct and opposing effects of COX1 and COX2 products on systemic blood pressure response to Ang II in anesthetized mice. In control mice, Ang II infusion caused a prompt increase in MAP (Figure 2a), followed by a gradual decline. The mechanism of the spontaneous fall in blood pressure could relate to desensitization of the Ang II receptors (40), or the synthesis of compensatory vasodilators, such as nitric oxide, bradykinin, or vasodepressor prostanoids $(9,41)$. In the presence of a COX2 inhibitor, the initial increase in blood pressure was accentuated, and the subsequent spontaneous decline markedly attenuated.

Chronic COX2 inhibition may theoretically reduce circulating levels of endogenous renin and Ang II, thereby sensitizing the vasculature to the pressor effects of exogenous Ang II infusion. Previous studies have demonstrated that COX2 activity stimulates renin synthesis and increases plasma renin activity; however, this has been reported only in the setting of a low-salt diet or angiotensin converting enzyme (ACE) inhibition (42-44). In the present studies, animals were not on a low-salt diet, and there is little evidence that COX2 activity promotes renin synthesis in animals on a sodium-replete diet (45-47). Furthermore, intravenous infusion of a COX2 inhibitor acutely increased the pressor effect of Ang II after its pressor effect was already established (Figure 2a). These data are consistent with a vasodepressor role for COX2-derived products. Acutely blocking the synthesis of these products, dramatically enhances the pressor effects of Ang II.

In mice lacking COX1 activity, Ang II transiently induced a similar pressor response as seen in controls. However, subsequently the MAP fell dramatically in COX1-deficient mice. These results suggest that COX1-derived products help sustain the pressor effects

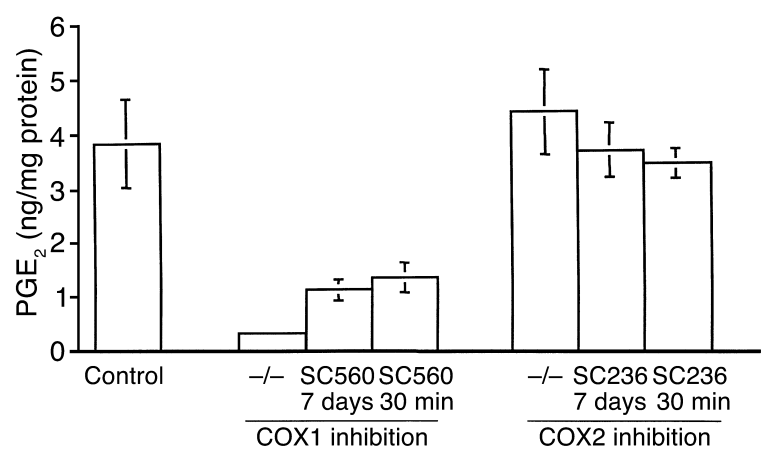

Figure 7

$\mathrm{PGE}_{2}$ production in gastric mucosa from control, COX1-deficient, and COX2-deficient animals. From left to right, the bars represent $\mathrm{PGE}_{2}$ level in controls $(n=4)$, COX1 knockout mice (COX1/-, $\left.n=10\right)$, mice pretreated with the COX1 inhibitor for 7 days $(n=8)$, mice receiving acute infusion of the COX 1 inhibitor for 30 minutes $(n=11)$, COX2 knockout mice $(n=7)$, mice pretreated with the COX2 inhibitor for 7 days $(n=8)$, and mice receiving acute infusion of the COX2 inhibitor for 30 minutes $(n=12) . P<0.05$ in all three groups with COX1 inhibition vs. controls, or vs. each group with COX 2 inhibition. 
of Ang II. Previous studies examining Ang II-dependent hypertension support a role for constrictor prostanoids and have implicated $\mathrm{PGH}_{2}, \mathrm{TxA}_{2}$, or $\mathrm{PGF}_{2 \alpha}$ as potential mediators $(48,49)$. Other studies suggest that $\mathrm{PGE}_{2}$ could also subserve this vasoconstrictor role $(16,17,19,50)$. The present studies now suggest that these constrictor prostanoids may derive from COX1 as opposed to COX2. Interestingly, COX1 was not detected by immunostaining in renal vessels including outer medullary vascular bundles (Figure 4). Whether COX1 is expressed in vascular resistance beds in other tissues, or the hemodynamic effect of COX1 inhibitors is mediated by inhibition of COX1 in circulating elements such as platelets, remains to be determined. Identification of the COX1-derived prostanoids mediating the vasoconstrictor action of Ang II, observed in the present studies, awaits definition of the relevant COX1-expressing tissues or vascular beds.

To gain further insight into the hemodynamic effects of COX1 and COX2 inhibitors, renal cortical and medullary blood flow was assessed using laser-Doppler flowmetry. As reported in other species (51), infusion of Ang II did not change MBF in untreated wild-type mice. Surprisingly, COX1 deficiency did not affect MBF either in the absence or in the presence of Ang II. In contrast, Ang II significantly reduced MBF when COX2 was inhibited by either SC58236 or gene disruption (Figure 3, b and d). Since Ang II infusion increased MAP significantly more in these same COX2deficient animals, we conclude that COX2 inhibition reduces renal MBF by increasing renal vascular resistance, presumably accentuating Ang II-induced constriction of renal microvasculature (52). Conversely, in control animals, the constrictor effects of Ang II are countered by augmented production of $\mathrm{COX} 2$-derived vasodilators, so $\mathrm{MBF}$ remains unchanged.

COX 1 and COX 2 are differentially localized in mouse kidney, with COX1 predominating in the collecting duct and COX2 predominating in medullary interstitial cells. Ang II selectively stimulated $\mathrm{PGE}_{2}$ and $\mathrm{PGI}_{2}$ production in the renal medulla. This was completely blocked by COX2 deletion yet still occurred in COX1-deficient mice. Taken together with immunolocalization of COX2 in medullary interstitial cells and COX1 in the collecting duct, it is plausible that Ang II only stimulates renal medullary $\mathrm{PGE}_{2}$ and $\mathrm{PGI}_{2}$ via COX2 synthesis in interstitial cells, which produces a renal medullary vasodilator action. These data are consistent with in vitro studies showing that Ang II directly stimulates prostaglandin synthesis in cultured renal medullary interstitial cells (53). Accumulating evidence suggests that COX2 may also be differentially responsible for systemic $\mathrm{PGI}_{2}$ and $\mathrm{PGE}_{2}$ production in humans, whereas COX1 mediates synthesis of thromboxane $(15,54,55)$. Taken together with the present data, COX2-derived $\mathrm{PGI}_{2}$ or $\mathrm{PGE}_{2}$ might also mediate compensatory systemic vasodilation, buffering the pressor effect of Ang II, while COX1derived constrictor prostanoids (perhaps an endoperoxide) might help sustain the pressor effects of Ang II.
Renal MBF has been intimately linked to the control of systemic blood pressure and renal sodium excretion (29). MBF positively correlates with and is a determinant of renal salt excretion $(29,56)$. These considerations are consistent with the present observations that in addition to reducing MBF, acute infusion of a COX2 inhibitor dramatically reduced urine volume and sodium excretion. COX1 was also abundantly expressed in the renal medulla; however, in contrast to COX2 it predominates in the collecting duct, a major site of salt and water absorption. Acute infusion of a COX1 inhibitor did not affect MBF, and despite its abundant expression in the collecting duct, its inhibition did not affect renal sodium or water excretion, or modify Ang II-induced diuresis or natriuresis. Since only COX2 inhibition decreased urine flow, its inhibition may account for the sodium retention and edema associated with NSAIDs and COXIB use in humans (3). These findings also suggest that reduced renal MBF could contribute to salt retention.

Clinical use of COX2 inhibitors in humans may also be complicated by the exacerbation of, and/or development of, hypertension $(2,3)$. Increased urinary salt excretion constitutes a critical adaptation, mitigating the development of hypertension (39). The present observations that COX2 inhibition blunts Ang II-induced natriuresis (Figure 6c) suggest that COX2 generates prostaglandins that promote renal salt excretion. It is well established that treatment of in vitro microperfused medullary thick ascending limbs or collecting ducts with basolateral $\mathrm{PGE}_{2}$ inhibits $\mathrm{NaCl}$ absorption in these segments (57-60). The demonstration that COX2 is expressed in medullary interstitial cells adjacent to these segments, coupled with the observation that Ang II stimulates renal medullary synthesis of $\mathrm{PGE}_{2}$ and $\mathrm{PGI}_{2}$ via COX2, is consistent with a model whereby Ang II promotes natriuresis, in part, via a paracrine effect of $\mathrm{PGE}_{2}$ inhibiting salt absorption by collecting ducts and thick ascending limbs (57-60). By blocking $\mathrm{PGE}_{2}$ and $\mathrm{PGI}_{2}$ synthesis, COX2 inhibitors simultaneously enhance epithelial salt absorption and further constrict vascular resistance beds. These events could conspire to result in hypertension and edema in humans. Whether the present findings, obtained in anesthetized animals, will also pertain to hypertensive models in conscious animals, or animals treated with other vasopressors, remains to be determined.

The renal papilla receives less than $1 \%$ of total renal blood flow primarily through the descending vasa recta (29). This low flow rate translates into a hypoxic environment that, combined with ambient hypertonicity, places significant stress on medullary cell viability (61). Reduced MBF associated with use of COX2 inhibitors could contribute to our previous observations that combined dehydration and COX2 inhibition cause apoptosis of medullary interstitial cells (32, 62). Similar circumstances could contribute to NSAID-associated papillary necrosis or analgesic nephropathy in humans (63). 
Selectivity of the COX1 inhibitor SC58560 and the COX2 inhibitor SC58236 used in the present studies has been demonstrated in vitro $(14,62,64)$. In vivo studies documented selective inhibition of COX1mediated rat gastric mucosal $\mathrm{PGE}_{2}$ production by SC58560 (14) with a trivial effect on COX2-mediated LPS-stimulated $\mathrm{PGE}_{2}$ production $(14,65)$. In the present studies, we demonstrated that either acute infusion or chronic oral pretreatment with the COX1 inhibitor dramatically inhibited gastric $\mathrm{PGE}_{2}$ production compared with control (Figure 7). In contrast, pretreatment with the COX2 inhibitor did not inhibit $\mathrm{PGE}_{2}$ synthesis by gastric mucosa. Finally, effects of the COX1 and COX2 inhibitors were specific, since they were faithfully reproduced in COX2 and COX1 knockout mice. Although interpretation of renal function in $\mathrm{COX}^{-/-}$ mice could be complicated by the associated renal cortical dysplasia (35), the fact that nearly identical results were obtained in mice with normal kidneys treated with SC58236 mitigates this concern. The present data further confirm the in vivo selectivity of these two COX isozyme-selective inhibitors.

The present studies demonstrate divergent effects of COX1 and COX2 activity on the responses of systemic and renal hemodynamics to Ang II in anesthetized mice. It remains to be determined whether the effects of COX isozyme-selective inhibitors and gene deletion also apply to the acute regulation of hemodynamics in conscious animals and animal models of chronic hypertension. In addition, the mice used in the present study were female. Further studies will also be needed to determine whether COX1 or COX2 activity modulates the hemodynamic response to Ang II similarly in male mice, or other strains of mice.

In summary, the present studies define distinct roles for COX1 and COX2 in regulating blood pressure and renal function in anesthetized mice. Rather than functionally synergizing or supplementing each other, the hemodynamic effects of COX2- and COX1-derived prostanoids appear to oppose each other. COX2 inhibition enhanced and prolonged the vasopressor effect of Ang II, while COX1 inhibition diminished the pressor effect of Ang II. COX2 inhibition was associated with decreased Ang II-stimulated renal $\mathrm{PGE}_{2}$ and $\mathrm{PGI}_{2}$ production. Renal MBF, urine volume, and sodium excretion were all significantly reduced by COX2 but not COX1 inhibition. These findings support the conclusion that COX2 rather than COX1 inhibition contributes to the development of hypertension, salt retention, and edema associated with NSAID use. Furthermore, these findings suggest that selective COX1 inhibitors could exhibit a favorable cardiovascular profile, simultaneously reducing blood pressure and inhibiting platelet-dependent microthrombotic events.

\section{Acknowledgments}

This study was supported by National Institute of Diabetes and Digestive and Kidney Diseases (NIDDK) grant NIDDK RO1-DK-37097 (to M.D. Breyer and R.M.
Breyer). M.D. Breyer is also the recipient of a Veterans Administration Merit Award. J.D. Morrow was supported by NIH grants DK-48831, CA-77839, and GM15431.J.D. Morrow is also the recipient of a Burroughs Wellcome Fund Clinical Scientist Award in Translational Research. The authors also wish to thank the investigators at Pharmacia (especially Peter Isakson and Karen Seibert) for providing the isoform-selective COX inhibitors SC58560 and SC58236.

1. FitzGerald, G.A., and Patrono, C. 2001. The coxibs, selective inhibitors of cyclooxygenase-2. N. Engl. J. Med. 345:433-442.

2. Breyer, M.D., and Harris, R.C. 2001. Cyclooxygenase 2 and the kidney. Curr. Opin. Nephrol. Hypertens. 10:89-98.

3. Whelton, A., et al. 2001. Cyclooxygenase-2-specific inhibitors and cardiorenal function: a randomized, controlled trial of celecoxib and rofecoxib in older hypertensive osteoarthritis patients. Am. J. Ther. 8:85-95.

4. Page, J., and Henry, D. 2000. Consumption of NSAIDs and the development of congestive heart failure in elderly patients: an underrecognized public health problem. Arch. Intern. Med. 160:777-784.

5. DeWitt, D.L., and Smith, W.L. 1988. Primary structure of prostaglandin $\mathrm{G} / \mathrm{H}$ synthase from sheep vesicular gland determined from the complementary DNA sequence. Proc. Natl. Acad. Sci. USA. 85:1412-1416.

6. Xie, W.L., Chipman, J.G., Robertson, D.L., Erikson, R.L., and Simmons, D.L. 1991. Expression of a mitogen-responsive gene encoding prostaglandin synthase is regulated by mRNA splicing. Proc. Natl. Acad. Sci. USA. 88:2692-2696.

7. Kujubu, D.A., Fletcher, B.S., Varnum, B.C., Lim, R.W., and Herschman, H.R. 1991. TIS10, a phorbol ester tumor promoter-inducible mRNA from Swiss 3T3 cells, encodes a novel prostaglandin synthase/cyclooxygenase homologue. J. Biol. Chem. 266:12866-12872.

8. Nasjletti, A. 1998. Arthur C. Corcoran Memorial Lecture. The role of eicosanoids in angiotensin-dependent hypertension. Hypertension. 31:194-200.

9. Siragy, H.M., Senbonmatsu, T., Ichiki, T., Inagami, T., and Carey, R.M. 1999. Increased renal vasodilator prostanoids prevent hypertension in mice lacking the angiotensin subtype-2 receptor. J. Clin. Invest. 104:181-188.

10. Kennedy, C.R., et al. 1999. Salt-sensitive hypertension and reduced fertility in mice lacking the prostaglandin EP2 receptor. Nat. Med. 5:217-220.

11. Smith, W.L., and Dewitt, D.L. 1996. Prostaglandin endoperoxide H synthases-1 and -2. Adv. Immunol. 62:167-215.

12. Breyer, M.D., et al. 1998. Regulation of renal function by prostaglandin E receptors. Kidney Int. Suppl. 67:S88-S94.

13. Smith, W.L., and Langenbach, R. 2001. Why there are two cyclooxygenase isozymes. J. Clin. Invest. 107:1491-1495.

14. Smith, C.J., et al. 1998. Pharmacological analysis of cyclooxygenase-1 in inflammation. Proc. Natl. Acad. Sci. USA. 95:13313-13318.

15. McAdam, B.F., et al. 1999. Systemic biosynthesis of prostacyclin by cyclooxygenase (COX)-2: the human pharmacology of a selective inhibitor of COX-2 [erratum 1999, 96:5890]. Proc. Natl. Acad. Sci. USA. 96:272-277.

16. Zhang, Y., et al. 2000. Characterization of murine vasopressor and vasodepressor prostaglandin E2 receptors. Hypertension. 35:1129-1134.

17. Audoly, L.P., et al. 2001. Role of EP(2) and EP(3) PGE(2) receptors in control of murine renal hemodynamics. Am. J. Physiol. Heart Circ. Physiol. 280:H327-H333.

18. Hoeper, M.M., et al. 2000. Long-term treatment of primary pulmonary hypertension with aerosolized iloprost, a prostacyclin analogue. N. Engl. J. Med. 342:1866-1870.

19. Tang, L., Loutzenhiser, K., and Loutzenhiser, R. 2000. Biphasic actions of prostaglandin $\mathrm{E}(2)$ on the renal afferent arteriole: role of $\mathrm{EP}(3)$ and $\mathrm{EP}(4)$ receptors. Circ. Res. 86:663-670.

20. Iwai, N., et al. 1999. Human prostacyclin synthase gene and hypertension: the Suita Study. Circulation. 100:2231-2236.

21. Fuse, S., and Kamiya, T. 1994. Plasma thromboxane B2 concentration in pulmonary hypertension associated with congenital heart disease. Circulation. 90:2952-2955.

22. Lawrence, R.A., and Jones, R.L. 1992. Investigation of the prostaglandin $\mathrm{E}$ (EP-) receptor subtype mediating relaxation of the rabbit jugular vein. Br. J. Pharmacol. 105:817-824.

23. Fitzpatrick, F.A., and Soberman, R. 2001. Regulated formation of eicosanoids. J. Clin. Invest. 107:1347-1351.

24. Brock, T.G., McNish, R.W., and Peters-Golden, M. 1999. Arachidonic acid is preferentially metabolized by cyclooxygenase- 2 to prostacyclin and prostaglandin E2. J. Biol. Chem. 274:11660-11666.

25. Kömhoff, M., Grone, H.J., Klein, T., Seyberth, H.W., and Nusing, R.M. 
1997. Localization of cyclooxygenase- 1 and -2 in adult and fetal human kidney: implication for renal function. Am. J. Physiol. 272:F460-F468

26. Harris, R.C., et al. 1994. Cyclooxygenase- 2 is associated with the macula densa of rat kidney and increases with salt restriction. J. Clin. Invest. 94:2504-2510.

27. Soler, M., Camacho, M., Escudero, J.R., Iniguez, M.A., and Vila, L. 2000 Human vascular smooth muscle cells but not endothelial cells express prostaglandin E synthase. Circ. Res. 87:504-507.

28. Penglis, P.S., Cleland, L.G., Demasi, M., Caughey, G.E., and James, M.J. 2000. Differential regulation of prostaglandin E2 and thromboxane A2 production in human monocytes: implications for the use of cyclooxygenase inhibitors. J. Immunol. 165:1605-1611.

29. Cowley, A., Mattson, D., Lu, S., and Roman, R. 1995. The renal medulla and hypertension. Hypertension. 25:663-673.

30. Edwards, A., Silldforff, E.P., and Pallone, T.L. 2000. The renal medullary microcirculation. Front. Biosci. 5:E36-E52.

31. Roman, R.J., and Lianos, E. 1990. Influence of prostaglandins on papillary blood flow and pressure-natriuretic response. Hypertension. 15:29-35.

32. Hao, C.M., et al. 2000. Dehydration activates an NF-kappaB-driven, COX2-dependent survival mechanism in renal medullary interstitial cells. J. Clin. Invest. 106:973-982.

33. Kömhoff, M., et al. 2000. Cyclooxygenase-2-selective inhibitors impair glomerulogenesis and renal cortical development. Kidney Int. 57:414-422.

34. Langenbach, R., et al. 1995. Prostaglandin synthase 1 gene disruption in mice reduces arachidonic acid-induced inflammation and indomethacin-induced gastric ulceration. Cell. 83:483-492.

35. Morham, S.G., et al. 1995. Prostaglandin synthase 2 gene disruption causes severe renal pathology in the mouse. Cell. 83:473-482.

36. Coffey, R.J., et al. 1997. Epidermal growth factor receptor activation induces nuclear targeting of cyclooxygenase-2, basolateral release of prostaglandins, and mitogenesis in polarizing colon cancer cells. Proc. Natl. Acad. Sci. USA. 94:657-662.

37. Masferrer, J.L., et al. 1994. Selective inhibition of inducible cyclooxygenase 2 in vivo is antiinflammatory and nonulcerogenic. Proc. Natl. Acad. Sci. USA. 91:3228-3232.

38. Guan, Y., et al. 1997. Cloning, expression, and regulation of rabbit cyclooxygenase- 2 in renal medullary interstitial cells. Am. J. Physiol. 273:F18-F26.

39. Guyton, A.C. 1991. Blood pressure control: special role of the kidneys and body fluids. Science. 252:1813-1816.

40. Balmforth, A.J., Shepherd, F.H., Warburton, P., and Ball, S.G. 1997. Evidence of an important and direct role for protein kinase $\mathrm{C}$ in agonistinduced phosphorylation leading to desensitization of the angiotensin AT1A receptor. Br. J. Pharmacol. 122:1469-1477.

41. Tsutsumi, Y., et al. 1999. Angiotensin II type 2 receptor overexpression activates the vascular kinin system and causes vasodilation. J. Clin. Invest. 104:925-935.

42. Harris, R.C., and Breyer, M.D. 2001. Physiological regulation of cyclooxygenase-2 in the kidney. Am. J. Physiol. Renal Physiol. 281:F1-F11.

43. Harding, P., et al. 1997. Cyclooxygenase- 2 mediates increased renal renin content induced by low-sodium diet. Hypertension. 29:297-302.

44. Traynor, T.R., Smart, A., Briggs, J.P., and Schnermann, J. 1999. Inhibition of macula densa-stimulated renin secretion by pharmacological blockade of cyclooxygenase-2. Am. J. Physiol. 277:F706-F710.

45. Cheng, H.F., et al. 2001. Genetic deletion of COX-2 prevents increased renin expression in response to ACE inhibition. Am. J. Physiol. Renal Phys iol. 280:F449-F456.
46. Castrop, H., et al. 2000. Cyclooxygenase 2 and neuronal nitric oxide synthase expression in the renal cortex are not interdependent in states of salt deficiency. Pflugers Arch. 441:235-240.

47. Castrop, H., Schweda, F., Schumacher, K., Wolf, K., and Kurtz, A. 2001. Role of renocortical cyclooxygenase-2 for renal vascular resistance and macula densa control of renin secretion. J. Am. Soc. Nephrol. 12:867-874.

48. Pagano, P.J., Lin, L., Sessa, W.C., and Nasjletti, A. 1991. Arachidonic acid elicits endothelium-dependent release from the rabbit aorta of a constrictor prostanoid resembling prostaglandin endoperoxides. Circ. Res. 69:396-405.

49. Mistry, M., and Nasjletti, A. 1988. Role of pressor prostanoids in rats with angiotensin II-salt-induced hypertension. Hypertension. 11:758-762.

50. Sessa, W.C., Lin, L., and Nasjletti, A. 1990. Reciprocal effects of dexamethasone on vasodilatory responses to arachidonic. Hypertension. 15:193-196.

51. Lu, S., Mattson, D.L., Roman, R.J., Becker, C.G., and Cowley, A.W., Jr. 1993. Assessment of changes in intrarenal blood flow in conscious rats using laser-Doppler flowmetry. Am. J. Physiol. 264:F956-F962.

52. Pallone, T.L., Silldorff, E.P., and Turner, M.R. 1998. Intrarenal blood flow: microvascular anatomy and the regulation of medullary perfusion. Clin. Exp. Pharmacol. Physiol. 25:383-392.

53. Zusman, R.L., and Keiser, H.R. 1977. Prostaglandin biosynthesis by rabbit renomedullary interstitial cells in tissue culture. Stimulation by angiotensin II, bradykinin, and arginine vasopressin. J. Clin. Invest. 60:215-223.

54. Whelton, A., et al. 2000. Effects of celecoxib and naproxen on renal function in the elderly. Arch. Intern. Med. 160:1465-1470.

55. Catella-Lawson, F., et al. 1999. Effects of specific inhibition of cyclooxygenase-2 on sodium balance, hemodynamics, and vasoactive eicosanoids. J. Pharmacol. Exp. Ther. 289:735-741.

56. Mattson, D.L., Roman, R.J., and Cowley, A.W., Jr. 1992. Role of nitric oxide in renal papillary blood flow and sodium excretion. Hypertension. 19:766-769.

57. Stokes, J.B., and Kokko, J.P. 1977. Inhibition of sodium transport by prostaglandin E2 across the isolated perfused rabbit collecting tubule. J. Clin. Invest. 52:1099-1104.

58. Hebert, R.L., Jacobson, H.R., and Breyer, M.D. 1991. Prostaglandin E2 inhibits sodium transport in rabbit cortical collecting duct by increasing intracellular calcium. J. Clin. Invest. 87:1992-1998.

59. Breyer, M.D., and Breyer, R.M. 2000. Prostaglandin E receptors and the kidney. Am. J. Physiol. Renal Physiol. 279:F12-F23.

60. Stokes, J.B. 1979. Effect of prostaglandin E2 on chloride transport across the rabbit thick ascending limb of Henle. Selective inhibitions of the medullary portion. J. Clin. Invest. 64:495-502.

61. Dinour, D., and Brezis, M. 1991. Effects of adenosine on intrarenal oxygenation. Am. J. Physiol. 261:F787-F791.

62. Hao, C.M., Komhoff, M., Guan, Y., Redha, R., and Breyer, M.D. 1999. Selective targeting of cyclooxygenase- 2 reveals its role in renal medullary interstitial cell survival. Am. J. Physiol. 277:F352-F359.

63. De Broe, M.E., and Elseviers, M.M. 1998. Analgesic nephropathy. N. Engl. J. Med. 338:446-452.

64. Penning, T.D., et al. 1997. Synthesis and biological evaluation of the 1,5diarylpyrazole class of cyclooxygenase- 2 inhibitors: identification of 4-[5-(4-methylphenyl)-3-(trifluoromethyl)-1H-pyrazol-1-yl]benzenesulfonamide (SC-58635, celecoxib). J. Med. Chem. 40:1347-1365.

65. Seibert, K., et al. 1994. Pharmacological and biochemical demonstration of the role of cyclooxygenase 2 in inflammation and pain. Proc. Natl. Acad. Sci. USA. 91:12013-12017. 